\title{
The Role of Sleep Curtailment on Leptin Levels in Obesity and Diabetes Mellitus
}

\author{
Maryam Mosavat ${ }^{\mathrm{a}}$ Mitra Mirsanjari $^{\mathrm{b}}$ Diana Arabiat ${ }^{\mathrm{a}, \mathrm{c}}$ Aisling Smyth ${ }^{\mathrm{a}}$ \\ Lisa Whitehead ${ }^{a}$ \\ ${ }^{a}$ School of Nursing and Midwifery, Edith Cowan University, Joondalup, WA, Australia; ${ }^{\text {b } M a z a n d a r a n ~ U n i v e r s i t y ~}$ \\ of Medical Sciences, Emam Khomeini Hospital, Mazandaran, Iran; 'Maternal and Child Nursing Department, \\ The University of Jordan, Amman, Jordan
}

\section{Keywords}

Short sleep duration · Leptin · Obesity · Diabetes

\begin{abstract}
Emerging evidence has identified sleep as a significant, but modifiable, risk factor for metabolic syndrome, diabetes, and obesity. Leptin, an adipocyte-derived peptide and a regulator of food intake and energy expenditure, has been shown to be associated with a short sleep duration in the pathophysiology of obesity and consequently type 2 diabetes. This review focuses on the current evidence indicating the effects of a short sleep duration on the regulation of leptin concentration in association with obesity and diabetes mellitus. In summary, the evidence suggests that sleep deprivation, by affecting leptin regulation, may lead to obesity and consequently development of type 2 diabetes through increased appetite and food intake. However, findings on the role of leptin in diabetes due to sleep deprivation are contradictory, and further studies with larger sample sizes are needed to confirm previous findings.

(c) 2021 The Author(s) Published by S. Karger AG, Basel
\end{abstract}

\begin{tabular}{ll}
\hline karger@karger.com & ( ) 2021 The Author(s) \\
www.karger.com/ofa & Published by S. Karger AG, Basel \\
& This article is licensed under the Creative Commons Attribution- \\
Karger & NonCommercial-NoDerivatives 4.0 International License (CC BY- \\
NC-ND) (http://www.karger.com/Services/OpenAccessLicense). & Usage and distribution for commercial purposes as well as any dis- \\
tribution of modified material requires written permission.
\end{tabular}

\section{Introduction}

Sleep is a biological and behavioral process that is fundamental for life and optimum health. Sleep is controlled by diurnal, homeostatic, and neurohormonal mechanisms [1]. Existing research acknowledges that sleep is an essential modulator of cardiovascular function, glucose regulation, and hormonal release [2]. Sleep duration has also been shown to have a pivotal function in metabolic hormones and body weight and it has been linked to other biological mechanisms including inflammation, the autonomic nervous system, the coagulation system, endothelial function, and metabolic regulation $[3,4]$. Sleep quality varies in individuals according to factors such as age, gender, occupation, educational level, socioeconomic status, race, family relationships, and pathological conditions including insomnia, depression level, and sleepdisordered breathing [5-7]. According to the US NationalSleep Foundation, adequate sleep duration requirements vary across lifespans and from person to person, with 7$9 \mathrm{~h}$ recommended for adults $[8,9]$. In recent decades, the average sleep duration has decreased worldwide, and this is widely attributed to a modern lifestyle [10]. Based on National Sleep Foundation criteria, 75\% of preadoles-

Maryam Mosavat

School of Nursing and Midwifery, Edith Cowan University

270 Joondalup Dr.

Joondalup, WA 6027 (Australia)

m.mosavat@ecu.edu.au 
cents and $45 \%$ of late adolescents experience sleep deficiency [11].

Insufficient sleep is characterized by either a considerable reduction in sleep time during a certain period due to 24-h wakefulness or a reduction in sleep time less than the optimal level for individual needs. Sleep loss, related to a decreased total sleep time, can be a result of habitual behavior or the presence of a pathological condition including addiction (medications or alcohol), anxiety, depression, idiopathic, somatic and painful diseases, and subjective and psychophysiological insomnia [12].

The reports from recent epidemiological studies, meta-analyses, and systematic reviews have indicated that sleep duration is significantly correlated with several adverse health outcomes including diabetes mellitus, cardiovascular diseases, coronary heart diseases and stroke, dyslipidemia, hypertension, metabolic disease, obesity, and mortality [1, 13-20]. Recent evidence proposes that that relationship between a short sleep duration, obesity, and diabetes risk may include at least 3 pathways, i.e., (1) an altered glucose metabolism, (2) up-regulation of hunger and appetite or dysregulation of appetite/satiety hormones, and (3) down-regulation of energy expenditure [21].

Leptin, a metabolic hormone, has a pivotal function in balancing appetite and satiety via food intake regulation and energy homeostasis [22]. Leptin works in synergy with another metabolic hormone, i.e., ghrelin. Whereas leptin suppresses food intake and induces weight loss, ghrelin increasing hunger and food intake [22]. Leptin is the product of the ob gene, which has an impact on growth, metabolism, and reproduction [23, 24]. Leptin has several other biological roles in the body [24], including functions in glucose homeostasis via suppression of insulin production in pancreatic $\beta$ cells [25]. The regulation of diurnal blood leptin is controlled by multiple factors such as gender, age, feeding, fasting, sleep, obesity, and endocrine disorders [26]. The concentration of serum leptin is directly related to fat mass, where increased circulating leptin, termed leptin resistance, is related to obesity [27]. The proposed mechanisms involved in leptin resistance are comprised of a reduction in the number of leptin receptors, impairment of receptor function, a reduction in transport across the blood-brain barrier, and a circulating suppressor of leptin function [28]. Since a leptin deficit in lipodystrophy is accompanied by dysglycemia and insulin resistance, it is expected that glucose metabolism is affected by leptin resistance [28]. Defects or dysfunction in the leptin signaling pathway plays a role in the pathophysiology of obesity, diabetes mellitus, and cardiovascular disease, and downstream targets of leptin may have a therapeutic potential role in the management of diabetes $[29,30]$. Furthermore, the adiponectin-leptin ratio has been found to be significantly correlated with the insulin resistance index in diabetes mellitus [31-33]. Leptin stimulates cytokine activation and immune-cell proliferation, which predisposes to inflammatory conditions [34].

The evidence suggests a bidirectional relationship between sleep duration and leptin. Leptin has central neural specific effects beyond modulation of appetite alone [35]. Leptin concentrations display a circadian pattern, with its levels increasing during the first part of the night and then decreasing during the latter part of the night [36]. Furthermore, leptin has a function in preserving deep sleep by antagonizing the orexin neuron function in the hypothalamus [37]. The findings of animal studies presented that the orexin (hypocretin) system monitors sleep and wakefulness through interactions with the system that regulates energy homeostasis and facilitates adaptive intensification of arousal in response to fasting. The orexin neuron actions are inhibited by leptin, blood glucose, and food intake [37-39]. An animal study in leptin-resistant $(\mathrm{db} / \mathrm{db})$ genetically obese and diabetic mice showed that impaired leptin signaling had deleterious impacts on the regulation of sleep duration [40]. This study proposed that leptin signaling plays an important role in coordination of sleep-wake states and metabolism. It appears that sleep-related changes in leptin level promote progression of metabolic and immune disorders. Leptin's proinflammatory role [24, 41, 42] proposes that increased serum leptin levels in metabolic syndrome and obesity in a sleep deprivation status may be associated with low-grade systemic inflammatory diseases, characterized by increased proinflammatory cytokine levels including interleukin-6 and tumor necrosis factor (TNF)- $\alpha$. Leptin regulates the brain appetite-regulating center with information about energy balance [43]. It has been believed that there is an interaction between leptin and insulin in peripheral tissues $[44,45]$. Leptin inhibits energy storage mechanisms, whereas insulin enhances leptin production [46]. Evidence also indicates that leptin promotes insulin sensitivity through enhancement of fatty acid oxidation and declined fat accumulation in non-adipose tissues. Leptin induces fatty acid oxidation in muscle via AMP-activated protein kinase (AMPK) [47]. Moreover, leptin has a significant role in increasing the glucose uptake in skeletal muscle through a $\beta$-adrenergic mechanism and the hypothalamic-sympathetic nervous system axis [47]. 
As one of the factors affecting leptin level regulation, the effect of sleep has been investigated in several experimental studies. Sleep loss with an effect on appetite hormone (leptin) and energy expenditure has been linked to an increased risk of obesity and diabetes. This review aims to provide an update on the influence of short sleep duration on leptin levels in association with obesity and diabetes mellitus.

\section{Data Sources and Searches}

PubMed, Google Scholar, and Science Direct were searched using the following terms: "leptin," "sleep duration," "sleep length," "sleep period," "sleep deprivation," "sleep deficiency," "sleep curtailment," "sleep loss," "short sleep duration," "diabetes," "weight gain," and "obesity." Original articles, reviews, and conference abstracts were included. Hand searching of reference lists was undertaken to identify any additional eligible studies. Publication dates were limited to 2000-2020, and papers written in English were included.

\section{Sleep Duration, Leptin, and Obesity}

Obesity, the result of a modern lifestyle, has progressively increased globally over the past century. The obesity epidemic and its consequent metabolic dysfunctions have been paralleled by the reduction in sleep duration $[48,49]$. It has been suggested by recent studies that sleep restriction adversely affects metabolic homeostasis, leading to increased hunger and appetite, and food intake, which consequently leads to insulin resistance $[49,50]$. The appetite hormones ghrelin and leptin work in synergy to manage hunger and satiety. Ghrelin, a stomachderived peptide, increases appetite [51], while leptin sends a message to the brain and suppresses appetite [52]. Appetite hormones rise throughout the day to a peak at 1:00 p.m. and then decrease overnight to a nadir at 9:00 p.m., which might be the cause of low leptin levels in short sleepers [53]. It has been proposed that dysregulated leptin and ghrelin play a key role in the increased BMI in short sleepers [4]. In an early study by Spiegel et al. [54], 2 days of sleep restriction $(4 \mathrm{~h})$ reduced leptin $(18 \%)$ and elevated ghrelin levels (28\%), indicative of an enhanced drive to eat (hunger, $24 \%$; appetite, $23 \%$ ) in young, healthy men. A study by Taheri et al. [4] showed that sleep duration below $7.7 \mathrm{~h}$ was associated with decreased leptin and increased ghrelin concentrations and consequently an in- creased body mass. These researchers suggested that a leptin deficiency increases appetite and consequently may cause obesity. The Child and Adolescent Metabolic Syndrome cohort studies $[55,56]$ suggested that a short sleep duration $(<8 \mathrm{~h} /$ day), compared to a long ( $\geq 10 \mathrm{~h} /$ day) sleep duration, affects the association of polygenic risk for obesity and the leptin pathway explains a key mechanism through a modification effect.

Thus far, there are conflicting results regarding leptin circulation in sleep curtailment, with its level being shown to be reduced [4, 57-59], unchanged [60-62], or elevated [63-67]. Chaput et al. [57], in their study in adults, reported that a sleep duration of 5-6 h/day was associated with a reduction in leptin levels and an increased risk of obesity and overweight compared to 7-8 and 9-10 h/day. A study in postmenopausal women showed that a sleep duration of less than $6 \mathrm{~h}$ per night was associated with lower serum leptin level compared to a sleep duration of more than $8 \mathrm{~h}$ [59]. In a study in healthy men, Mullington et al. [58] reported a rapid reduction in leptin amplitude in that sleep deprivation period, which returned toward normal during the period of recovery sleep. Spiegel et al. [68] evaluated associations between leptin and sympathovagal balance, cortisol, thyroid-stimulating hormone (thyrotropin or TSH), glucose, and insulin under different bedtime conditions. They reported that sleep restriction ( $4 \mathrm{~h}$ for 6 nights) was associated with a decrease in the mean and maximal levels and rhythm amplitude of leptin $(-19,-26$, and $-20 \%$, respectively) compared to an extended sleep time ( $12 \mathrm{~h}$ for 7 nights). The effects of a short sleep duration on leptin level have also been shown to be associated with an elevation of sympathovagal balance and alterations in the cortisol and TSH profiles [68]. The thyroid gland regulates thermogenesis (body temperature) and appetite, and its dysfunction (hypothyroidism or hyperthyroidism) results in alterations in body mass [69]. Furthermore, higher TSH levels are associated with obesity and a higher body mass [70-72]. The exact mechanism underlying the influence of TSH on obesity is still unclear, but increases in energy expenditure and hyperleptinemia have been proposed to be influenced in this relationship [69].

Although short-term sleep curtailment has been shown to be associated with activation of the stress system, which leads to decreased leptin levels and increased hunger and appetite, acute loss of sleep in a less stressful environment has been shown to increase leptin levels in the body [66]. Therefore, it seems that a combination of sleep curtailment and activation of the stress system but not sleep loss itself may lead to decreased leptin levels and 
increased hunger [66]. Hayes et al. [65] have examined the level of leptin in association with a reduced sleep time among adults. They reported that a 1-h decrease in total sleep duration was associated with a $10 \%$ increase in leptin levels [65]. A study on salivary cortisol and leptin in young healthy women showed that a single night of restricted sleep $(3 \mathrm{~h})$ altered the diurnal pattern of cortisol rhythms (the level of morning cortisol was reduced, and afternoon/evening cortisol levels were elevated) and increased morning leptin levels in subjects but it did not have an effect on hunger and craving scores [67]. BosyWestphal et al. [73] found that consecutive nightly decreases in sleep duration significantly increased body weight, energy intake, glucose-induced thermogenesis, leptin/fat mass, free triiodothyronine, and free thyroxine [73]. Charles et al. [74] showed that both short $(<5 \mathrm{~h})$ and long $(>8 \mathrm{~h})$ sleep durations were associated with increased leptin levels related to obesity.

However, unaffected leptin levels have been reported in patients with a sleep deficiency [61]. In a study in men with and without insomnia, circulating levels of leptin and ghrelin were measured across the night. Serial measurement of appetite hormones showed that ghrelin levels were significantly lower in insomnia patients, whereas leptin did not differ between the groups. Furthermore, the findings of this study concluded that dysregulation in energy balance in patients with insomnia results in weight gain in this population [61]. A Circadian Locomotor Output Cycles Kaput (CLOCK) gene study showed that a shorter sleep duration increased ghrelin levels with no effects on leptin values [60]. This study suggested that sleep reduction with alterations in ghrelin levels and changes in eating behaviors may affect weight and weight loss. Schmid et al. [62], in a study in healthy normal-weight men, reported that feelings of hunger and ghrelin levels were elevated after 1 night of total sleep deprivation, whereas morning serum leptin concentrations was unaffected. A large multiethnic study also found no association between sleep duration and leptin levels [75].

\section{Sleep Duration, Leptin, and Diabetes}

Sleep plays a critical role in glucose regulation, and sleep duration has been shown to have an inverse effect on endocrine function and carbohydrate metabolism $[2,76]$. The link between sleep and glucose metabolism has been explored in several studies, where it has been proposed that both short $[13,77-80]$ and long sleep durations [8183] may increase the risk of developing obesity and con-

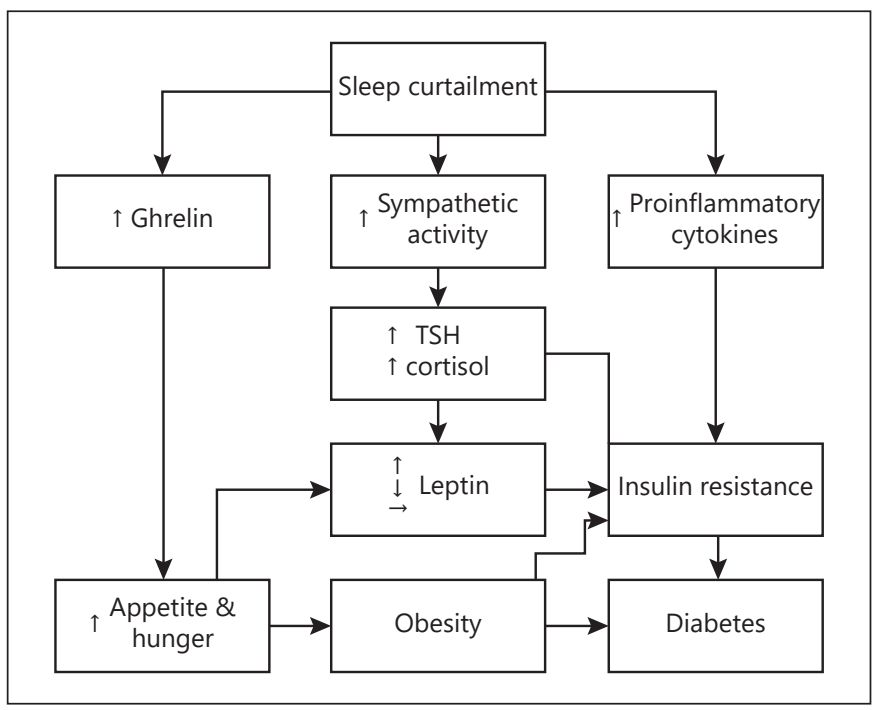

Fig. 1. Role of sleep restriction on leptin regulation in obesity and diabetes.

sequently diabetes mellitus. It was shown by a systematic and meta-analysis study that both short and long sleep durations in type 2 diabetes patients is significantly associated with an increase in hemoglobin Alc (HbAlc) levels, suggesting poorer glycemic control compared to that with a normal sleep duration, with the relationship being Ushaped [84]. In another study both a short sleep duration (>5.5 and 5.5-6.4 h) and a long sleep duration (7.5-8.4 h) were associated with an increase in the risk of metabolic syndrome, insulin resistance, and high-sensitivity C-reactive protein in diabetic patients compared to those with $6.5-7.4 \mathrm{~h}$ of sleep [85]. These findings also concluded that sleep duration has a U-shaped relationship with metabolic syndrome and insulin resistance. A recent meta-analysis confirmed that short sleep ( $>6$ compared to $7 \mathrm{~h}$ ) may increase the risk of type 2 diabetes by approximately $30 \%$ [86]. It has been proposed that sleep deprivation impairs insulin sensitivity and pancreatic $\beta$-cell function and glucose uptake by target cells, increasing insulin resistance and leading to type 2 diabetes [87-94]. Recent evidence suggests that the metabolic hormones leptin and ghrelin are involved in the relationship between sleep and dysregulation of insulin and glucose and increase the risk of diabetes [63, 68, 94-97]. Given the effects of sleep deficiency on leptin levels and metabolism, a short sleep duration may mediate its effects on incident diabetes through weight gain $[98,99]$ (Fig. 1).

The reviews on the role of sleep restriction in the metabolic and endocrine alterations propose that a decreased 
sleep duration impairs glucose tolerance and insulin sensitivity, increases evening concentrations of cortisol and levels of ghrelin, decreases levels of leptin, and increases appetite and hunger $[100,101]$.

In contrast, a multiethnic study in a population at high risk for diabetes showed that a short sleep duration $(\leq 5.5$ h) was associated with an increase in leptin levels [75]. A study in diabetic patients showed that an insufficient sleep duration increased the level of leptin and insulin resistance compared to those with an appropriate sleep duration [102]. A laboratory-based sleep study showed that sleep restriction (5 nights of $4 \mathrm{~h}$ in bed) impaired glucose homeostasis and increased fasting and insulin levels [63]. Sleep restriction was associated with an increase in afternoon cortisol and leptin levels compatible with an increased insulin resistance [63]. It has been reported that a 1 -h reduction in sleep duration was associated with a $7 \%$ elevation in leptin levels [65]. Furthermore, a study in rotating-shift-work women reported an inverse association between leptin levels and the risk of type 2 diabetes. However, there was no association between sleep duration, leptin levels, and diabetes [103].

Considering the role of leptin in regulation of energy consumption, a decrease in the production of leptin due to a lack of sleep may explain the contribution of adjustment of this hormone to obesity, decreased insulin sensitivity, and increased insulin resistance. It is noteworthy that elevation of serum leptin levels results in decreased leptin transport across the blood-brain barrier [104]. It has been indicated that when leptin reaches its threshold the blood-brain barrier limits the leptin transport from peripheral blood to the central nervous system, inhibiting its activity [105]. This condition may explain the elevation of leptin levels due to sleep restriction, where the effectiveness of it is attenuated. In this way, leptin resistance, characterized by a decreased response to leptin due to a reduced receptor expression, is another possible mechanism that explains elevated leptin levels in the blood but decreased leptin effects [28]. Thus, in the case of elevated plasma leptin levels it does not consistently reflect increased leptin efficacy and function in glucose homeostasis [28].

In summary, recent evidence indicates that an insufficient sleep duration, with an effect on leptin metabolism, may promote the development of type 2 diabetes through increased hunger/food intake and weight gain. Furthermore, leptin dysregulation contributes to decreased insulin secretion and sensitivity, increased insulin resistance and inflammation, and consequently an increased risk of diabetes mellitus. Several studies have in- vestigated the role of a short sleep duration on leptin regulation; however, the findings regarding the role of leptin in diabetes as a consequence of sleep curtailment are conflicting and more studies with a larger sample size are required to confirm the previous findings.

\section{Strengths and Limitations}

We reviewed and discussed the probable mechanism underlying the effect of sleep duration on leptin regulation as the potential physiological mechanism underlying obesity and type 2 diabetes. Potential limitations of this work include the conflation of sleep quality and sleep duration where these were not always reported separately in the studies included in this review. Furthermore, this review was conducted as a narrative review and as such a quality appraisal of the included papers was not undertaken. Further work is required to compare the findings of both sleep quality and duration on leptin circulation related to obesity and diabetes.

\section{Conflict of Interest Statement}

The authors declare that there is no conflict of interest regarding the publication of this article.

\section{Funding Sources}

There were no funding sources for this work.

\section{Author Contributions}

Maryam Mosavat drafted this paper. Mitra Mirsanjari, Diana Arabiat, Aisling Smyth, and Lisa Whitehead reviewed and revised this work. All authors read and approved the final version of this article.

\section{References}

$$
\begin{aligned}
& 1 \text { Shan Z, Ma H, Xie M, Yan P, Guo Y, Bao W, } \\
& \text { et al. Sleep duration and risk of type } 2 \text { diabe- } \\
& \text { tes: a meta-analysis of prospective studies. Di- } \\
& \text { abetes Care. } 2015 \text { Mar;38(3):529-37. } \\
& 2 \text { Van Cauter E, Spiegel K, Tasali E, Leproult R. } \\
& \text { Metabolic consequences of sleep and sleep } \\
& \text { loss. Sleep Med. 2008 Sep;9(1):S23-8. } \\
& 3 \text { Tobaldini E, Fiorelli EM, Solbiati M, Costan- } \\
& \text { tino G, Nobili L, Montano N. Short sleep du- } \\
& \text { ration and cardiometabolic risk: from patho- } \\
& \text { physiology to clinical evidence. Nat Rev Car- } \\
& \text { diol. } 2019 \text { Apr;16(4):213-24. }
\end{aligned}
$$

Obes Facts 2021;14:214-221 DOI: $10.1159 / 000514095$
Mosavat/Mirsanjari/Arabiat/Smyth/ Whitehead 
4 Taheri S, Lin L, Austin D, Young T, Mignot E. Short sleep duration is associated with reduced leptin, elevated ghrelin, and increased body mass index. PLoS Med. 2004 Dec; 1(3):e62.

5 Heinzer R, Vat S, Marques-Vidal P, MartiSoler H, Andries D, Tobback N, et al. Prevalence of sleep-disordered breathing in the general population: the HypnoLaus study. Lancet Respir Med. 2015 Apr;3(4):310-8.

6 Park C, Sim CS, Sung JH, Lee J, Ahn JH, Choe $\mathrm{YM}$, et al. Low Income as a Vulnerable Factor to the Effect of Noise on Insomnia. Psychiatry Investig. 2018 Jun;15(6):602-12.

7 Ruggiero AR, Peach HD, Gaultney JF. Association of sleep attitudes with sleep hygiene, duration, and quality: a survey exploration of the moderating effect of age, gender, race, and perceived socioeconomic status. Health Psychol Behav Med. 2019 Jan;7(1):19-44.

8 Hirshkowitz M, Whiton K, Albert SM, Alessi C, Bruni O, DonCarlos L, et al. National Sleep Foundation's updated sleep duration recommendations: final report. Sleep Health. 2015 Dec;1(4):233-43.

9 Hirshkowitz M, Whiton K, Albert SM, Alessi C, Bruni O, DonCarlos L, et al. National Sleep Foundation's sleep time duration recommendations: methodology and results summary. Sleep Health. 2015 Mar;1(1):40-3.

10 Van Cauter E, Knutson KL. Sleep and the epidemic of obesity in children and adults. Eur J Endocrinol. 2008 Dec;159 Suppl 1:S59-66.

11 Miguez MJ, Bueno D, Perez C. Disparities in sleep health among adolescents: the role of sex, age, and migration. Sleep Disord. 2020 Jan;2020:5316364.

12 Medic G, Wille M, Hemels ME. Short- and long-term health consequences of sleep disruption. Nat Sci Sleep. 2017 May;9:151-61.

13 Itani O, Jike M, Watanabe N, Kaneita Y. Short sleep duration and health outcomes: a systematic review, meta-analysis, and meta-regression. Sleep Med. 2017 Apr;32:246-56.

14 Cappuccio FP, Cooper D, D’Elia L, Strazzullo $\mathrm{P}$, Miller MA. Sleep duration predicts cardiovascular outcomes: a systematic review and meta-analysis of prospective studies. Eur Heart J. 2011 Jun;32(12):1484-92.

15 Cappuccio FP, D’Elia L, Strazzullo P, Miller MA. Quantity and quality of sleep and incidence of type 2 diabetes: a systematic review and meta-analysis. Diabetes Care. $2010 \mathrm{Feb}$; 33(2):414-20

16 Wang Y, Mei H, Jiang YR, Sun WQ, Song YJ, Liu SJ, et al. Relationship between duration of sleep and hypertension in adults: a meta-analysis. J Clin Sleep Med. 2015 Sep;11(9):104756.

17 Chaput JP, McNeil J, Després JP, Bouchard C, Tremblay A. Short sleep duration as a risk factor for the development of the metabolic syndrome in adults. Prev Med. 2013 Dec;57(6): $872-7$.
18 Shen X, Wu Y, Zhang D. Nighttime sleep duration, 24-hour sleep duration and risk of allcause mortality among adults: a meta-analysis of prospective cohort studies. Sci Rep. 2016 Feb;6(1):21480.

$19 \mathrm{Wu}$ Y, Zhai L, Zhang D. Sleep duration and obesity among adults: a meta-analysis of prospective studies. Sleep Med. 2014 Dec;15(12): 1456-62.

20 Leng Y, Cappuccio FP, Wainwright NW, Surtees PG, Luben R, Brayne C, et al. Sleep duration and risk of fatal and nonfatal stroke: a prospective study and meta-analysis. Neurology. 2015 Mar;84(11):1072-9.

21 Knutson KL, Spiegel K, Penev P, Van Cauter E. The metabolic consequences of sleep deprivation. Sleep Med Rev. 2007 Jun;11(3):16378.

22 Klok MD, Jakobsdottir S, Drent ML. The role of leptin and ghrelin in the regulation of food intake and body weight in humans: a review. Obes Rev. 2007 Jan;8(1):21-34.

23 Denver RJ, Bonett RM, Boorse GC. Evolution of leptin structure and function. Neuroendocrinology. 2011;94(1):21-38.

24 Fantuzzi G, Faggioni R. Leptin in the regulation of immunity, inflammation, and hematopoiesis. J Leukoc Biol. 2000 Oct;68(4):43746.

25 Wang C, Guan Y, Yang J. Cytokines in the progression of pancreatic $\beta$-cell dysfunction. Int J Endocrinol. 2010;2010:515136.

26 Pan W, Kastin AJ. Leptin: a biomarker for sleep disorders? Sleep Med Rev. 2014 Jun; 18(3):283-90.

27 Zhou Y, Rui L. Leptin signaling and leptin resistance. Front Med. 2013 Jun;7(2):207-22.

28 Gruzdeva O, Borodkina D, Uchasova E, Dyleva Y, Barbarash O. Leptin resistance: underlying mechanisms and diagnosis. Diabetes Metab Syndr Obes. 2019 Jan;12:191-8.

29 Meek TH, Morton GJ. Leptin, diabetes, and the brain. Indian J Endocrinol Metab. 2012 Dec;16(9 Suppl 3):S534-42.

30 Meek TH, Morton GJ. The role of leptin in diabetes: metabolic effects. Diabetologia. 2016 May;59(5):928-32.

31 Oda N, Imamura S, Fujita T, Uchida Y, Inagaki $\mathrm{K}$, Kakizawa $\mathrm{H}$, et al. The ratio of leptin to adiponectin can be used as an index of insulin resistance. Metabolism. 2008 Feb;57(2): 268-73.

32 Zaletel J, Barlovic DP, Prezelj J. Adiponectinleptin ratio: a useful estimate of insulin resistance in patients with Type 2 diabetes. J Endocrinol Invest. 2010 Sep;33(8):514-8.

33 Mosavat M, Omar SZ, Tan PC, Razif MF, Sthaneshwar P. Leptin and soluble leptin receptor in association with gestational diabetes: a prospective case-control study. Arch Gynecol Obstet. 2018 Mar;297(3):797-803.

34 Peelman F, Waelput W, Iserentant H, Lavens D, Eyckerman S, Zabeau L, et al. Leptin: linking adipocyte metabolism with cardiovascular and autoimmune diseases. Prog Lipid Res. $2004 \mathrm{Jul} ; 43(4): 283-301$.
35 Olson CA, Hamilton NA, Somers VK. Percentage of REM sleep is associated with overnight change in leptin. J Sleep Res. 2016 Aug; 25(4):419-25.

36 Licinio J, Mantzoros C, Negrão AB, Cizza G, Wong ML, Bongiorno PB, et al. Human leptin levels are pulsatile and inversely related to pituitary-adrenal function. Nat Med. 1997 May; 3(5):575-9.

37 Hirota T, Morioka T, Yoda K, Toi N, Hayashi $\mathrm{N}$, Maruo $\mathrm{S}$, et al. Positive association of plasma leptin with sleep quality in obese type 2 diabetes patients. J Diabetes Investig. 2018 Sep;9(5):1100-5.

38 Yamanaka A, Beuckmann CT, Willie JT, Hara J, Tsujino N, Mieda M, et al. Hypothalamic orexin neurons regulate arousal according to energy balance in mice. Neuron. 2003 Jun; 38(5):701-13.

39 Sakurai T. The neural circuit of orexin (hypocretin): maintaining sleep and wakefulness. Nat Rev Neurosci. 2007 Mar;8(3):171-81.

40 Laposky AD, Bradley MA, Williams DL, Bass J, Turek FW. Sleep-wake regulation is altered in leptin-resistant $(\mathrm{db} / \mathrm{db})$ genetically obese and diabetic mice. Am J Physiol Regul Integr Comp Physiol. 2008 Dec;295(6):R2059-66.

41 Jahromi AS, Zareian P, Madani A. Association of insulin resistance with serum interleukin- 6 and TNF- $\alpha$ levels during normal pregnancy. Biomark Insights. 2011;6:BMI-S6150.

$42 \mathrm{Xu}$ LL, Shi CM, Xu GF, Chen L, Zhu LL, Zhu $\mathrm{L}$, et al. TNF- $\alpha$, IL-6, and leptin increase the expression of miR-378, an adipogenesis-related microRNA in human adipocytes. Cell Biochem Biophys. 2014 Nov;70(2):771-6.

43 Timper K, Brüning JC. Hypothalamic circuits regulating appetite and energy homeostasis: pathways to obesity. Dis Model Mech. 2017 Jun;10(6):679-89.

44 Amitani M, Asakawa A, Amitani H, Inui A. The role of leptin in the control of insulinglucose axis. Front Neurosci. 2013 Apr;7:51.

45 D'souza AM, Neumann UH, Glavas MM, Kieffer TJ. The glucoregulatory actions of leptin. Mol Metab. 2017 May;6(9):1052-65.

46 Rosenbaum M, Leibel RL. 20 years of leptin: role of leptin in energy homeostasis in humans. J Endocrinol. 2014 Oct;223(1):T83-96.

47 Minokoshi Y, Toda C, Okamoto S. Regulatory role of leptin in glucose and lipid metabolism in skeletal muscle. Indian J Endocrinol Metab. 2012 Dec;16(9 Suppl 3):S562-8.

48 Beccuti G, Pannain S. Sleep and obesity. Curr Opin Clin Nutr Metab Care. 2011 Jul;14(4): 402-12.

49 Hakim F, Wang Y, Carreras A, Hirotsu C, Zhang J, Peris E, et al. Chronic sleep fragmentation during the sleep period induces hypothalamic endoplasmic reticulum stress and PTP1b-mediated leptin resistance in male mice. Sleep (Basel). 2015 Jan;38(1):31-40.

50 Seetho IW, Wilding JP. Screening for obstructive sleep apnoea in obesity and diabetes-potential for future approaches. Eur J Clin Invest. 2013 Jun;43(6):640-55. 
51 van der Lely AJ, Tschöp M, Heiman ML, Ghigo E. Biological, physiological, pathophysiological, and pharmacological aspects of ghrelin. Endocr Rev. 2004 Jun;25(3):426-57.

52 Zigman JM, Elmquist JK. Minireview: from anorexia to obesity - the yin and yang of body weight control. Endocrinology. 2003 Sep; 144(9):3749-56.

53 Cummings DE, Purnell JQ, Frayo RS, Schmidova $\mathrm{K}$, Wisse BE, Weigle DS. A preprandial rise in plasma ghrelin levels suggests a role in meal initiation in humans. Diabetes. 2001 Aug;50(8):1714-9.

54 Spiegel K, Tasali E, Penev P, Van Cauter E. Brief communication: sleep curtailment in healthy young men is associated with decreased leptin levels, elevated ghrelin levels, and increased hunger and appetite. Ann Intern Med. 2004 Dec;141(11):846-50.

55 Fu J, Wang Y, Li G, Han L, Li Y, Li L, et al. Childhood sleep duration modifies the polygenic risk for obesity in youth through leptin pathway: the Beijing Child and Adolescent Metabolic Syndrome cohort study. Int J Obes. 2019 Aug;43(8):1556-67.

56 Li M, Fu J, Han L, Li G, Gao S, Grant SF, et al. Childhood habitual sleep duration modifies the polygenic risk for obesity through leptin pathway: a longitudinal study. Diabetes. 2018 Jul;67.

57 Chaput JP, Després JP, Bouchard C, Tremblay A. Short sleep duration is associated with reduced leptin levels and increased adiposity: results from the Quebec family study. Obesity (Silver Spring). 2007 Jan;15(1):253-61.

58 Mullington JM, Chan JL, Van Dongen HP, Szuba MP, Samaras J, Price NJ, et al. Sleep loss reduces diurnal rhythm amplitude of leptin in healthy men. J Neuroendocrinol. 2003 Sep; 15(9):851-4.

59 Stern JH, Grant AS, Thomson CA, Tinker L, Hale L, Brennan KM, et al. Short sleep duration is associated with decreased serum leptin, increased energy intake and decreased diet quality in postmenopausal women. Obesity (Silver Spring). 2014 May;22(5):E55-61.

60 Garaulet M, Sánchez-Moreno C, Smith CE, Lee YC, Nicolás F, Ordovás JM. Ghrelin, sleep reduction and evening preference: relationships to CLOCK 3111 T/C SNP and weight loss. PLoS One. 2011 Feb;6(2):e17435.

61 Motivala SJ, Tomiyama AJ, Ziegler M, Khandrika S, Irwin MR. Nocturnal levels of ghrelin and leptin and sleep in chronic insomnia. Psychoneuroendocrinology. 2009 May;34(4): 540-5.

62 Schmid SM, Hallschmid M, Jauch-Chara K, Born J, Schultes B. A single night of sleep deprivation increases ghrelin levels and feelings of hunger in normal-weight healthy men. J Sleep Res. 2008 Sep;17(3):331-4.

63 Reynolds AC, Dorrian J, Liu PY, Van Dongen HP, Wittert GA, Harmer LJ, et al. Impact of five nights of sleep restriction on glucose metabolism, leptin and testosterone in young adult men. PLoS One. 2012;7(7):e41218.
64 Simpson NS, Banks S, Dinges DF. Sleep restriction is associated with increased morning plasma leptin concentrations, especially in women. Biol Res Nurs. 2010 Jul;12(1):47-53.

65 Hayes AL, Xu F, Babineau D, Patel SR. Sleep duration and circulating adipokine levels. Sleep (Basel). 2011 Feb;34(2):147-52.

66 Pejovic S, Vgontzas AN, Basta M, Tsaoussoglou M, Zoumakis E, Vgontzas A, et al. Leptin and hunger levels in young healthy adults after one night of sleep loss. J Sleep Res. 2010 Dec;19(4):552-8.

67 Omisade A, Buxton OM, Rusak B. Impact of acute sleep restriction on cortisol and leptin levels in young women. Physiol Behav. 2010 Apr;99(5):651-6.

68 Spiegel K, Leproult R, L'hermite-Balériaux M, Copinschi G, Penev PD, Van Cauter E. Leptin levels are dependent on sleep duration: relationships with sympathovagal balance, carbohydrate regulation, cortisol, and thyrotropin. J Clin Endocrinol Metab. 2004 Nov;89(11): 5762-71.

69 Fontenelle LC, Feitosa MM, Severo JS, Freitas TE, Morais JB, Torres-Leal FL, et al. Thyroid Function in Human Obesity: underlying Mechanisms. Horm Metab Res. 2016 Dec; 48(12):787-94.

70 Xu R, Huang F, Zhang S, Lv Y, Liu Q. Thyroid function, body mass index, and metabolic risk markers in euthyroid adults: a cohort study. BMC Endocr Disord. 2019 Jun;19(1):58.

71 Solanki A, Bansal S, Jindal S, Saxena V, Shukla US. Relationship of serum thyroid stimulating hormone with body mass index in healthy adults. Indian J Endocrinol Metab. 2013 Oct; 17(7 Suppl 1):S167-9.

72 Sanyal D, Raychaudhuri M. Hypothyroidism and obesity: an intriguing link. Indian J Endocrinol Metab. 2016 Jul-Aug;20(4):554-7.

73 Bosy-Westphal A, Hinrichs S, Jauch-Chara K, Hitze B, Later W, Wilms B, et al. Influence of partial sleep deprivation on energy balance and insulin sensitivity in healthy women. Obes Facts. 2008;1(5):266-73.

74 Charles LE, Gu JK, Andrew ME, Violanti JM, Fekedulegn D, Burchfiel CM. Sleep duration and biomarkers of metabolic function among police officers. J Occup Environ Med. 2011 Aug;53(8):831-7.

75 Brady EM, Bodicoat DH, Hall AP, Khunti K, Yates T, Edwardson C, et al. Sleep duration, obesity and insulin resistance in a multi-ethnic UK population at high risk of diabetes. Diabetes Res Clin Pract. 2018 May; 139:195202.

76 Van Cauter E, Holmbäck U, Knutson K, Leproult R, Miller A, Nedeltcheva A, et al. Impact of sleep and sleep loss on neuroendocrine and metabolic function. Horm Res. 2007;67 Suppl 1:2-9.

77 Gutiérrez-Repiso C, Soriguer F, Rubio-Martín E, Esteva de Antonio I, Ruiz de Adana MS, Almaraz MC, et al. Night-time sleep duration and the incidence of obesity and type 2 diabetes. Findings from the prospective Pizarra study. Sleep Med. 2014 Nov;15(11):1398-404.
78 Schultes B, Schmid S, Peters A, Born J, Fehm HL. Sleep loss and the development of diabetes: a review of current evidence. Exp Clin Endocrinol Diabetes. 2005 Dec;113(10):563-7.

79 Lou P, Zhang P, Zhang L, Chen P, Chang G, Zhang N, et al. Effects of sleep duration and sleep quality on prevalence of type 2 diabetes mellitus: A 5-year follow-up study in China. Diabetes Res Clin Pract. 2015 Jul;109(1):17884.

80 Jackson CL, Redline S, Kawachi I, Hu FB. Association between sleep duration and diabetes in black and white adults. Diabetes Care. 2013 Nov;36(11):3557-65.

81 Tan X, Chapman CD, Cedernaes J, Benedict C. Association between long sleep duration and increased risk of obesity and type 2 diabetes: A review of possible mechanisms. Sleep Med Rev. 2018 Aug;40:127-34.

82 Jike M, Itani O, Watanabe $\mathrm{N}$, Buysse DJ, Kaneita Y. Long sleep duration and health outcomes: A systematic review, meta-analysis and meta-regression. Sleep Med Rev. 2018 Jun;39:25-36.

83 Azharuddin M, Kapur P, Adil M, Ghosh P, Sharma M. The impact of sleep duration and sleep quality on glycaemic control in Asian population with type 2 diabetes mellitus: A systematic literature review and meta-analysis of observational studies. Clin Epidemiol Glob Health. 2020 Mar;8(3):967-75.

84 Lee SW, Ng KY, Chin WK. The impact of sleep amount and sleep quality on glycemic control in type 2 diabetes: A systematic review and meta-analysis. Sleep Med Rev. 2017 Feb; 31:91-101.

85 Ohkuma T, Fujii H, Iwase M, Ogata-Kaizu S, Ide $\mathrm{H}$, Kikuchi $\mathrm{Y}$, et al. U-shaped association of sleep duration with metabolic syndrome and insulin resistance in patients with type 2 diabetes: the Fukuoka Diabetes Registry. Metabolism. 2014 Apr;63(4):484-91.

86 Holliday EG, Magee CA, Kritharides L, Banks E, Attia J. Short sleep duration is associated with risk of future diabetes but not cardiovascular disease: a prospective study and metaanalysis. PLoS One. 2013 Nov;8(11):e82305.

87 Wong PM, Manuck SB, DiNardo MM, Korytkowski M, Muldoon MF. Shorter sleep duration is associated with decreased insulin sensitivity in healthy white men. Sleep (Basel). 2015 Feb;38(2):223-31.

88 Wang X, Greer J, Porter RR, Kaur K, Youngstedt SD. Short-term moderate sleep restriction decreases insulin sensitivity in young healthy adults. Sleep Health. 2016 Mar;2(1):63-8.

89 Rao MN, Neylan TC, Grunfeld C, Mulligan K, Schambelan M, Schwarz JM. Subchronic sleep restriction causes tissue-specific insulin resistance. J Clin Endocrinol Metab. 2015 Apr;100(4):1664-71.

90 Donga E, van Dijk M, van Dijk JG, Biermasz NR, Lammers GJ, van Kralingen KW, et al. A single night of partial sleep deprivation induces insulin resistance in multiple metabolic pathways in healthy subjects. J Clin Endocrinol Metab. 2010 Jun;95(6):2963-8. 
91 Pyykkönen AJ, Isomaa B, Pesonen AK, Eriksson JG, Groop L, Tuomi T, et al. Subjective sleep complaints are associated with insulin resistance in individuals without diabetes: the PPP-Botnia Study. Diabetes Care. 2012 Nov; 35(11):2271-8.

92 Damanti S, Bourron O, Doulazmi M, Mandengue Sosso AL, Nguyen-Michel VH, Mariani J, et al. Relationship between sleep parameters, insulin resistance and age-adjusted insulin like growth factor-1 score in non diabetic older patients. PLoS One. 2017 Apr; 12(4):e0174876.

93 Chang JK, Koo M, Kao VY, Chiang JK. Association of sleep duration and insulin resistance in Taiwanese vegetarians. BMC Public Health. 2012 Aug;12(1):666.

94 Buxton OM, Pavlova M, Reid EW, Wang W, Simonson DC, Adler GK. Sleep restriction for 1 week reduces insulin sensitivity in healthy men. Diabetes. 2010 Sep;59(9):2126-33.

95 Grandner MA, Seixas A, Shetty S, Shenoy S. Sleep duration and diabetes risk: population trends and potential mechanisms. Curr Diab Rep. 2016 Nov; 16(11):106.
96 Broussard JL, Ehrmann DA, Van Cauter E, Tasali E, Brady MJ. Impaired insulin signaling in human adipocytes after experimental sleep restriction: a randomized, crossover study. Ann Intern Med. 2012 Oct;157(8):549-57.

97 Knutson KL, Van Cauter E. Associations between sleep loss and increased risk of obesity and diabetes. Ann N Y Acad Sci. 2008;1129(1): 287-304.

98 Ayas NT, White DP, Al-Delaimy WK, Manson JE, Stampfer MJ, Speizer FE, et al. A prospective study of self-reported sleep duration and incident diabetes in women. Diabetes Care. 2003 Feb;26(2):380-4.

99 Yaggi HK, Araujo AB, McKinlay JB. Sleep duration as a risk factor for the development of type 2 diabetes. Diabetes Care. 2006 Mar; 29(3):657-61.
100 Zimberg IZ, Dâmaso A, Del Re M, Carneiro AM, de Sá Souza H, de Lira FS, et al. Short sleep duration and obesity: mechanisms and future perspectives. Cell Biochem Funct. 2012 Aug;30(6):524-9.

101 Gangwisch JE. Epidemiological evidence for the links between sleep, circadian rhythms and metabolism. Obes Rev. 2009 Nov; 10 Suppl 2:37-45.

102 Jain SK, Kahlon G, Morehead L, Lieblong B, Stapleton T, Hoeldtke R, et al. The effect of sleep apnea and insomnia on blood levels of leptin, insulin resistance, IP-10, and hydrogen sulfide in type 2 diabetic patients. Metab Syndr Relat Disord. 2012 Oct;10(5):331-6.

103 Wang S, Fu W, Jiang Y, Deng L, Zhou S, Yang L. Association of plasma leptin levels with type 2 diabetes in rotating shift work women. Biomed Res (Aligarh). 2017 Jan; 28(1).

104 Banks WA. Role of the blood-brain barrier in the evolution of feeding and cognition. Ann N Y Acad Sci. 2012 Aug;1264(1):13-9.

105 Imayama I, Prasad B. Role of Leptin in Obstructive Sleep Apnea. Ann Am Thorac Soc. 2017 Nov; 14(11):1607-21. 